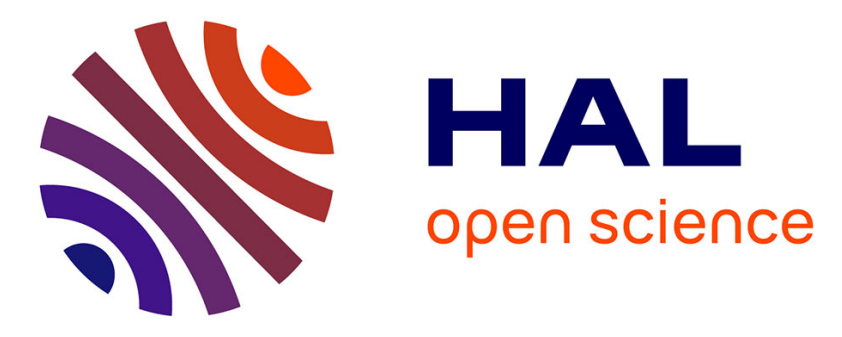

\title{
Sign Management for the Future of e-Education: Examples of Collaborative e-Services in a Living Lab (Invited Paper)
}

Noël Conruyt, Véronique Sébastien, Olivier Sébastien, Didier Sébastien, David Grosser

\section{To cite this version:}

Noël Conruyt, Véronique Sébastien, Olivier Sébastien, Didier Sébastien, David Grosser. Sign Management for the Future of e-Education: Examples of Collaborative e-Services in a Living Lab (Invited Paper). 2nd IFIP International Workshop on Artificial Intelligence for Knowledge Management (AI4KM), Sep 2014, Warsaw, Poland. pp.1-20, 10.1007/978-3-319-28868-0_1 . hal-01369798

\section{HAL Id: hal-01369798 \\ https://inria.hal.science/hal-01369798}

Submitted on 21 Sep 2016

HAL is a multi-disciplinary open access archive for the deposit and dissemination of scientific research documents, whether they are published or not. The documents may come from teaching and research institutions in France or abroad, or from public or private research centers.
L'archive ouverte pluridisciplinaire HAL, est destinée au dépôt et à la diffusion de documents scientifiques de niveau recherche, publiés ou non, émanant des établissements d'enseignement et de recherche français ou étrangers, des laboratoires publics ou privés.

\section{(c)(1)}

Distributed under a Creative Commons Attribution| 4.0 International License 


\title{
A Sign-based management methodology for co-designing educational e-services in Living Labs
}

\author{
Noël Conruyt, Véronique Sébastien, Olivier Sébastien, \\ Didier Sébastien and David Grosser \\ LIM, EA 25-25, University of Reunion Island, 97490, Sainte-Clotilde, France \\ \{noel.conruyt, veronique.sebastien, olivier.sebastien, \\ didier.sebastien, david.grosser\}@univ-reunion.fr
}

\begin{abstract}
From a European technological and industrial perspective of the $20^{\text {th }}$ century, knowledge management was viewed as the next step towards reaching a knowledge-based economy. But today, in the 21th century of fast moving information, we argue that knowledge management is not enough for reaching a knowledge-based post-industrial society. We need a broader view in order to understand user needs and respond to their desires. In this endeavor, Living labs are a good way to reposition the creative users at the center of technologies. But we need also methodologies and tools to accompany the transition from a competitive economy to a sustainable society. We experimented this move at University of Reunion Island in the domain of education with ICT. We conceived a new paradigm called sign management for enhancing content producers with multimedia tools on a creativity platform. A methodology for co-designing educational e-services was applied in both natural and cultural domains in order that linear knowledge transmission let place to an iterative know-how sharing approach between teachers and learners. This sign-based methodology serves as a condition for opening the era of semiotic Web, which is necessary for applying Living labs in real educational contexts, i.e. with training people.
\end{abstract}

Keywords: Sign-based management, Semiotic Web, E-service, Education, Living Lab, Creativity Platform.

\section{$1 \quad$ Introduction}

The Lisbon strategy of Europe [1] tried to make the EU "the most competitive and dynamic knowledge-based economy in the world capable of sustainable economic growth with more and better jobs and greater social cohesion", by 2010. But it failed because of a techno-centric approach of innovation principally focused on economic growth and forgetting the role of human beings in the development of a knowledge society that takes into account social and environmental awareness. A quick count at the report from the High Level Group [2] of the word competition on one hand (12 occurrences) and cooperation or collaboration on the other hand (4 occurrences) is enlightening. It shows the direction followed by EU in the new millennium for 
achieving the knowledge economy in a techno-centered industrial understanding of sustainability, moving first to economy (growth and jobs), then to social and environment resolution. The result is the one that is described by M. Luycks Ghisi [3] on knowledge society: the negative scenario of engineering the human mind and make a green washing of our environment to mask the aim of doing business as usual!

The positive scenario is another post-industrial vision, i.e. reaching a sign-based society. It is not only a matter of technological, economical, or social awareness; it is also grounded in individual, human, environmental and cultural values. Psychological, ethical, biological and emotional assets are indeed drivers of the future of a knowledge society in a perspective of sustainable development of services codesigned with people. Sustainability applied to innovation needs to give empowerment to users for them to drive new products and services that fit their real and useful needs.

In this paper, we will apply this vision of a sign-based society to the problem of education with Information and Communication Technologies (ICT). We will first explain the role of ICT in this change of paradigm for the Future Internet and Web. We will then analyze how Living Labs help us to manage this enlarged definition of ICT. Then, we will introduce our theory of sign management that is based on three levels of capacity: personal and phenomenal volition (Biological Semiotics), relational and verbal action (Activity Theory) and formal and written cognition (Signification Theory). This theory leads to the new paradigm of Semiotic Web that encompasses other Web dimensions, i.e. Social Semantic Immersive Web. This theory has been applied in our University of Reunion Island Living Lab for Teaching and Learning how to manage biodiversity and music heritage. We will show some examples of this new approach for innovating with users in real contexts. Lastly, we will introduce the concept of e-co-innovation that gives sense to a sustainable society based on motivation, action and understanding of the human signs, for some skilled users to co-design e-services that are really desirable, open, smart and inclusive.

\section{ICT in the future of a knowledge-based society}

For the objective of reaching the future of a knowledge-based society that we call a sign-based society, we need to understand the meaning of words that are currently used in our digital world (ICT, Internet, Web, Services, objects, etc.). For example, Figure 1 shows that ICT must not only be considered as technological tangible containers (Technologies), but also convey human contents (data, information, and knowledge). These intangible assets are communicated between users (Information and Communication) by the mean of products (virtual platforms), electronic services (e-services) and Web applications in the clouds.

At the upper level of ICT, there is the Web in real contexts with people. The Web is a service of Internet (as the email or the ftp) to connect producers and consumers of multimedia contents, in order that Internet infrastructures meet user needs [4]. Codesigning e-services with users is an iterative communication process that is central between Internet technology and Web usage. These collaboration principles have 
been adopted since 2006 by the European Network of Living Labs (ENoLL) and are developed in the frame of corresponding literature [5]. The changing world philosophy is that in a sustainable society, the political leaders must concentrate on the demand of subjects rather than on the offer of objects. The innovation path is to transform a quantitative strategy of things delivered massively on the Internet (IoTs) by a qualitative strategy of signs on the Web (WoSs) that are more personalized in order to be more meaningful for individuals and communities.

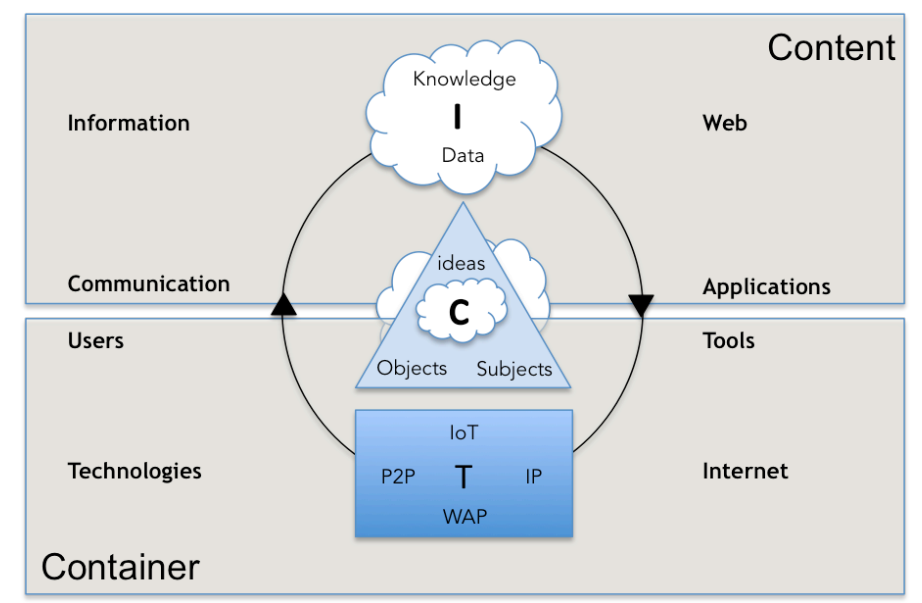

Fig. 1. ICT are not only a technological matter but also cloud services that matter!

Indeed, technologies are means, not objectives. As says Marc Giget, "Very few people fall in love of a Wireless Access Protocol!" So, innovation relies also in cocreating products and services that end-users would like and use. Some of them are researchers and specialists of a domain, such as in natural sciences or in arts. They acquired knowledge through their long practice of domain objects (species, pieces), and are recognized as experts by other practitioners. The amateurs would love to be educated by masters, but the physical distance is an obstacle for them to be taught. Indeed, the best way to learn a domain is to get a course with a professor. With ICT, finding solutions that recreate the conditions of a real course on the Web can tackle this distance educational problem and respond to real user needs.

\section{$3 \quad$ Setting up ICT Living Labs for education}

ICT Living Labs position themselves at the center of the process of convergence of containers and contents for making tools and applications. It can be represented by the triangle with the clouds' birth in Figure 1. They allow users (subjects) to communicate ideas between them about things (objects) in order to co-design new e-services on the Web. Arrows show that there is an iterative process to set up for building content applications that depend on container generator tools. Living Labs can help us to manage this iterative process of going from ideas to services and products. 
For us, a Living Lab (LL) is both a real and virtual environment for user-centered innovation, based on the observation of every-day user practice and experience for solving problems, but also based on their active participation, with an approach that facilitates their influence in the open and distributed innovation process (participatory design). It engages all concerned partners in the real-life contexts, and aims to create sustainable usage values [6]. As important effects, we reach relevant knowledge on the context of use, such as premature validations in the market, tries in environments familiar to the users, experience feedbacks of co-creative users of tools and applications [7]. This new innovation system is a human-centered ecosystem based on expert Knowledge, Business services and Social capital, i.e. the KBS Concurrent Innovation paradigm [8]. On a strategic plan, a LL is defined as a 4P innovation process, i.e. Public-Private Partnership with People. The objectives are political, focused on the social role of innovation, i.e. trying to realize totally the human potential by the increase of their creativity, rather than focalizing only on technological developments.

More specifically when one instantiates it in a domain such as Social $>$ Education, a Living Lab includes public and private actors, companies, associations, individual actors, whose objective is to co-design, to develop and to test life-size educational services, tools and new practices. The aim is to take out the Research $>$ Teaching of laboratories to make it come down in the daily life, often by having a strategic view on the potential uses of tools and applications for doing Business. All this takes place in cooperation between local authorities, companies, research laboratories, as well as potential users, via helping platforms for designing innovative e-services and analyzes of their usages. It is a question of favoring the culture of opening (open innovation), of sharing its networks, and of involving the users from the beginning of the conception.

The European Institute of Innovation and Technology (EIT) was created in 2008 as an independent body of the European Union to bring together leading higher education institutions, research labs and companies to form Knowledge Innovation Communities (KICs) that develop innovative products and services, start new companies, and train a new generation of entrepreneurs. Their mission is described in [9]. One of the KICs is devoted to ICT [10]. Figure 2 shows the Knowledge Triangle of EIT ICT Labs [11] that puts Knowledge at the center of the European vision in a Knowledgebased society.

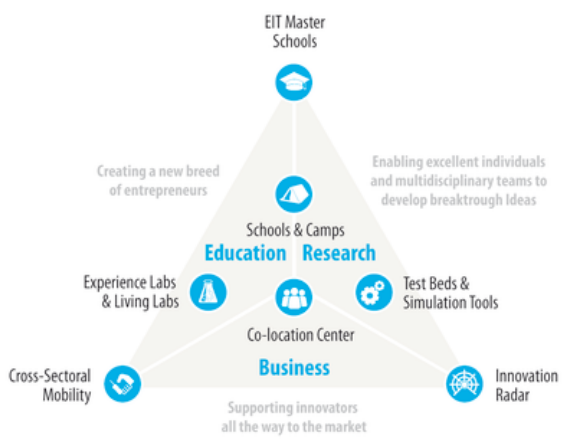

Fig. 2. The Knowledge Triangle 
In their vision, Living Labs are positioned in the educational part of the triangle for making experimentations and getting experience. The educational action process is described in [12] for teaching and learning in the knowledge triangle:

The knowledge triangle has so far mostly been presented as a theoretical concept and political desideratum over changes needed in Europe. This theoretical model now must be transformed into a model of action, an everyday working model for the people involved. One way is to create an enquiry based process around the three nodes of the triangle. Three questions need to be in the mind of everyone at all levels in the system and in all planning and performing: 1) What are the best ways of linking research to education? 2) What are the best ways of teaching creativity, innovation and entrepreneurship? and 3) How can optimal conditions be created for entrepreneurs and innovators to bring back their knowledge and experience back into research?

But in this process, they don't figure out the role of ICT in the triangle model. The knowledge triangle is a static descriptive view that could be enhanced with ICT by a new representation of Signs and a signification process (see the next section). For understanding it, Figure 3 shows that the triangle must be seen from the above and not from one side. The new representation that we propose for integration of ICT is a $3 \mathrm{D}$ tetrahedron model. The Living Lab stands at the center of the tetrahedron for communication purpose and ICT is fueling the convergence of Research, Education and Business with a new signification process.

In our view, we think that we must shift from a flat 2D triangle representation of Knowledge with its linear transmission (from Research to Education to Business), to a circular 3D tetrahedron representation of Signs (Data, Information, Knowledge, Subject) and their dynamic signification process (called semiosis) for sharing them. We will explain now this new iterative sign management process for the future of knowledge management with ICT.

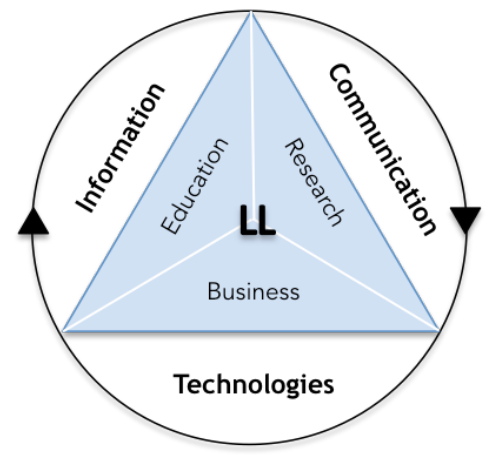

Fig. 3. The Living Lab Tetrahedron (seen from above) 


\section{Theory}

Sign Management emphasizes the engineering and use of data, information and knowledge from the viewpoint of an interpreter (Subject).

\section{Representation of Signs}

The concept of Sign is derived from the pragmatic and triadic Peirce's theory of semiotics with a Sign's correspondence of the Subject to its Object. From this philosophical viewpoint, a Sign, or representamen, is something that stands to somebody for something in some respect or capacity [13]. From our computer science analysis, Data (Object) is the content of the Sign (something), Information, a multi-layered concept with Latin roots ('informatio' = to give a form) is its form, and Knowledge is its sense or meaning, i.e. no-thing. The notion of Sign is then more central than knowledge for our purpose of designing e-services.

Moreover, as we want to compare different sign representations coming from different interpreters, we designed a fouradic representation of signs that can be communicated in a personalized way, i.e. through different interpretations of the same objet.

In Figure 4, we define the tetrahedral representation of a Sign as the interpretation of an Object by a Subject at a given time and place, which takes into account its content (Data, facts, events), its form (Information), and its sense or meaning (Knowledge).

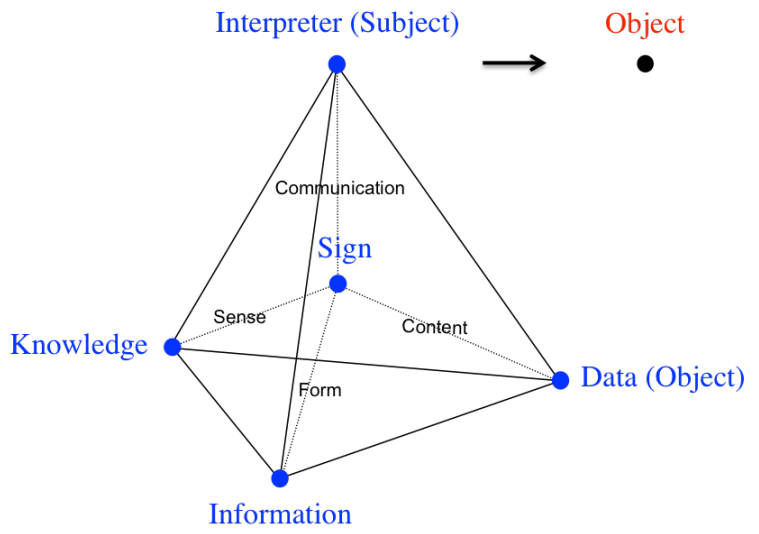

Fig. 4. The tetrahedron of the Sign (static representation)

This new representation of signs enhances the subjective aspect of knowledge that can be managed with ICT, because some interpreters are better than others for solving problems: their experience of specialist can be described and shown with multimedia contents in order to learn their good practices or know-how. Managing knowledge in general is not possible without managing personal know-how that gives birth to it. So, the problem is to wonder how to construct objective knowledge with ICT from different subject interpretations, which is the aim of science? 


\section{Signification / construction of Signs}

Knowledge is the ultimate goal of Science, but this target is difficult to reach without taking into account humans who generate it in a constructivist manner!

In Figure 5, we introduce Sign-ification, i.e. the continuous process of using Signs in human thinking for acquiring Objects interpreted by Subjects. This sign construction process or Semiosis takes the different components of the Sign in a certain order to make a decision: first comes the Subject or Interpreter who is receptive to his milieu or "Umwelt" [14], and who cares about Information to act in a certain direction (volition, conation). Then occurs the searched Data (Object) to position himself in space and time (action). Next, Knowledge is activated in his memory to compare the actual situation with his past experiences and make a hypothesis for taking a decision (cognition).

The signification or the building of the sign communicates the process iteratively in a reflexive way (in order to memorize new knowledge) or communicates the resulting interpretation as information to its environment (by exteriorization).

Semiosis is similar to the working principle of inference engine that was modeled in expert systems: the evaluation-execution cycle [15]. The difference is that Signification integrates the Subject in the process, and this integration is therefore more meaningful to humans than to machines. The Subject operates on Signs in two phases: reflection and action. These phases are inter-linked in a reflexive cycle with a semiotic spiral shape including six moments: 1) to desire, 2) to do, 3) to know, 4) to interpret, 5) to know-how for oneself, 6) to communicate to others (Figure 5). The semiosis spiral is included in the tetrahedron of the Sign.

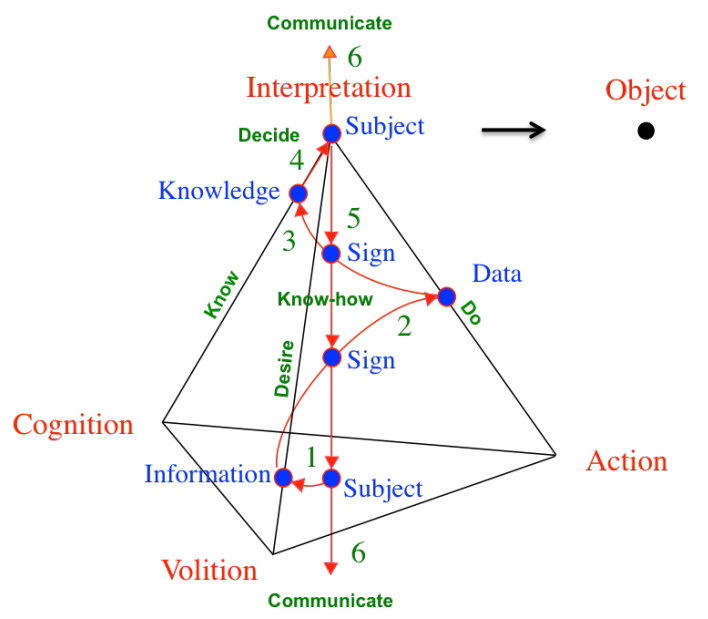

Fig. 5. The signification process (dynamic)

Consequently, Signification is the key psychological process that makes sense for practicing usage based research and development with people by communicating data, information and knowledge. Sign management is based on representation AND signi- 
fication of Signs at three levels of capacity: personal and phenomenal volition (Uexküll Biological Semiotics Theory), relational and verbal action (Engeström Activity Theory) and formal and written cognition (Peirce Signification Theory).

\section{Semiotic Web}

When an organism or an individual seeks for something, his attitude is to pay attention to events of his environment that go in the sense (direction) of what he searches. The primary intention of a microorganism such as bacteria is "good sense": it wants to capture information from the milieu to develop itself and stay alive [16].

Human development follows the same schema of self-organized living systems at more complex levels than these physiological and safety needs. They are those that have been defined in the hierarchy of fundamental individual needs: love, belonging, esteem, self-actualization [17].

As a consequence, we hold that before being able to make "true sense", i.e. adopt a scientific rationale, the objective of individuals is to respond to psychological needs (desire, pleasure, identity, etc.). This theory of human motivation is a natural and cultural hypothesis, which is corroborated by Umwelt [14], Activity [18] and Semiotic [13] pragmatic theories. These life and logical sciences are components of the Biosemiotics interdisciplinary research [19], which was introduced before the advent of Internet as the "Semiotic Web" [20].

By comparison, Semantic Web is the dyadic combination of form and sense of the linguistic Sign [21], taken as a signifier (form) and signified (sense). It is rational. Semiotic Web is more generic and living. It complements the Semantic Web (form and sense) with the referents (content) that are observed data (interpretations) georeferenced in a 3D information world (Immersive Web) as Web Services by subjects pertaining to communities of practice (Social Web 2.0). This makes our Sign management ecosystem a tetrahedron model (Figure 6) that is more involved in concrete life with end-users on a specific territory such as Reunion Island.

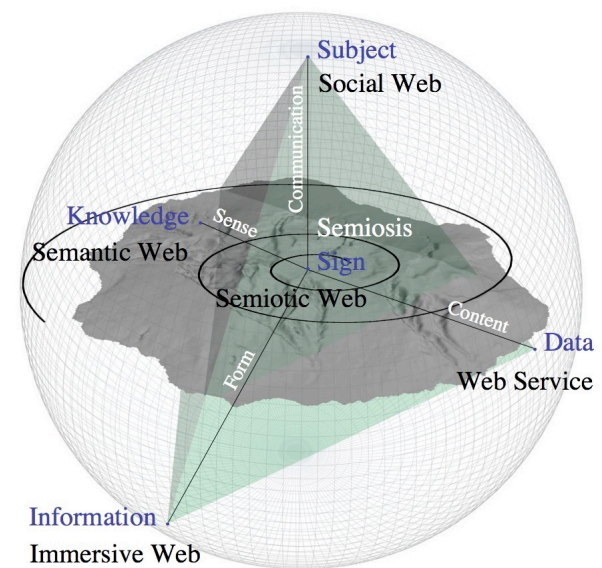

Fig. 6. The four dimensions of Semiotic Web: Service, Social, Semantic and Immersive Web 
The Web of Signs combines:

1. The Web of Data and Objects, i.e. the flow of raw and digital contents produced by specialists (teachers) and transmitted by engineers in databases and knowledge bases in the frame of an Information System (one-way flow), but progressively becoming interoperable through Web services with other Information Systems,

2. The Web of Subjects, i.e. a bidirectional communication platform between users (teachers and learners) using different e-services within a community of practice to exchange interpretations of data and objects, and negotiate their value,

3. The Web of Information that is geo localized in attractive virtual worlds representing the real landscape (metaverses), and accessible at any time, anywhere, on any devices (mobiquity).

4. The Web of Knowledge for machines to communicate logically on the basis of a formal, open and semantic representation of data and objects,

The Semiotic Web is for us the future of the Semantic Web: it is the Web of Signs rather than the Web of Things. The Semiotic Web is more general than the Semantic Web because it allows managing Signs (Data, Information, Knowledge) from a subjective viewpoint and not only Knowledge from an objective angle. Signification is the kernel of Semiotic Web although Representation is at the root of Semantic Web. Both are necessary to co-design e-services in the future Web, but from our experience, co-designing e-services with users needs to manage signs on a Creativity Platform for building e-services that match lead-users needs.

\section{$5 \quad$ Research design}

At the University of Reunion Island, we have investigated these different dimensions (phenomenal, relational and formal) that are converging to form what we call the Semiotic Web. As the World is an Island and as Reunion Island is a small world, we designed our Living Lab as a small laboratory for Teaching and Learning Sciences and Arts by Playing [22]. Indeed, edutainment is one of the pillars of the future Web [23]. With game-based learning, we consider that we can play seriously to better know our environment and then better protect it.

For making e-services, the first step is to generate ideas. This ideation process should be attractive for motivating some researchers to drive projects. Living Labs are those desirable innovation ecosystems (breeding grounds) for enhancing research and go to the market, i.e. make ideas become alive (emergence of ideas) towards products and services. The second step is then to co-design mock-ups and prototypes, and experiment them in a physical meeting place called the Creativity Platform (see below). Co-creation in communities of researchers, entrepreneurs and users is also a significant characteristic of open and social innovation that is part of the DNA of Living Labs for bringing trust between co-designers. The third step is to formalize a solution that fits user needs. It applies abductive, inductive and deductive science cognition principles and generates implicit knowledge (for self) or explicit knowledge (for others). Semantic knowledge is captured in knowledge bases with a tool called IKBS 
(Iterative Knowledge Base System) for defining written ontologies, describing use cases and making qualitative decisions with induction and case-based reasoning. Semiotic annotations with multimedia objects are proposed in order to illustrate the terms that are used in the ontology and in the cases.

\section{The Creativity Platform}

For the purpose of co-designing such a product/service with ICT, the Creativity Platform is the co-working, co-learning and communication space for researchers and developers, businesses and users, aimed at collectively defining the characteristics of e-services in order to ensure the most direct match between expectations and use.

In its technical form (see Figure 7 on the right), the Creativity Platform includes a multimedia platform as the one that we find in television studios, but also includes a physical and virtual place to discuss ideas and projects, make models and prototypes, and experiment them in a synchronous (focus group) or asynchronous (video forum on the Web) way.

From a pragmatic viewpoint (see Figure 7 on the left), a Creativity Platform is a meeting place and communication space for researchers and developers, businesses and users to pursue innovative and useful projects. For example, they are aimed at collectively defining the characteristics of e-services in order to ensure the most direct correspondence between expectations and use, by combining design and use approaches. Sign sharing makes use of the Creativity Platform by applying an iterative assessment process with end-users from the idea to the product/service through mockups and prototypes evaluation.

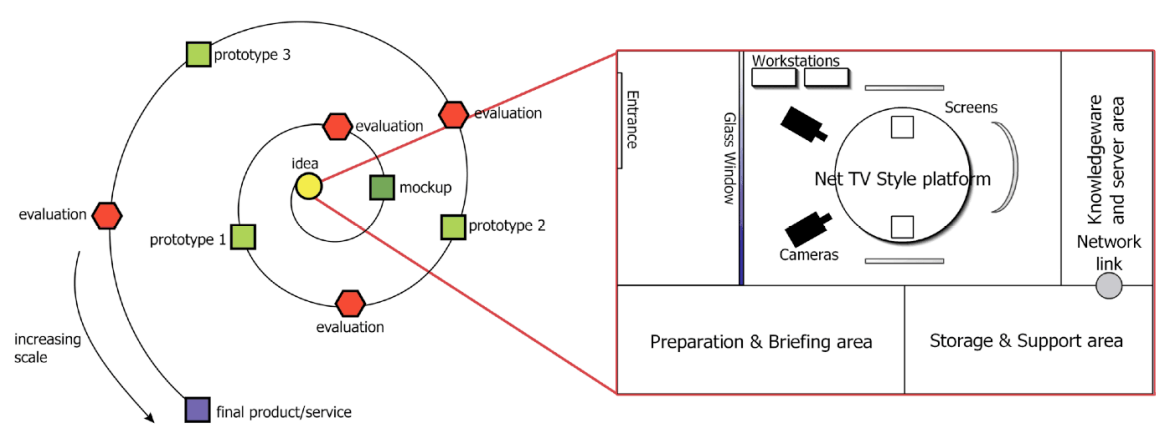

Fig. 7. The Creativity or Co-design Platform to experiment future products/services

\section{Co-design methodology}

A Creativity Platform is also called a Co-design Platform [24]. We conceived our own method of co-designing e-services on this Platform (Figure 8). From ideas to final product/services, resolutions are taken in the frame of funded projects that define the vision, the objectives, the plan and the evaluation phases (production process in a 
co-working mode on the left of figure 8). Assessments of future e-services are made by considering the usage side of the project: end-users have their own identities, activities, tasks and give meaning to the obtained results (usage process in a co-learning mode on the right of figure 8 ). To facilitate the decisions, the project managers (leadusers) are themselves practitioners of the domain. So they have an understanding of the solutions that they can design, deliver and experiment with other users.

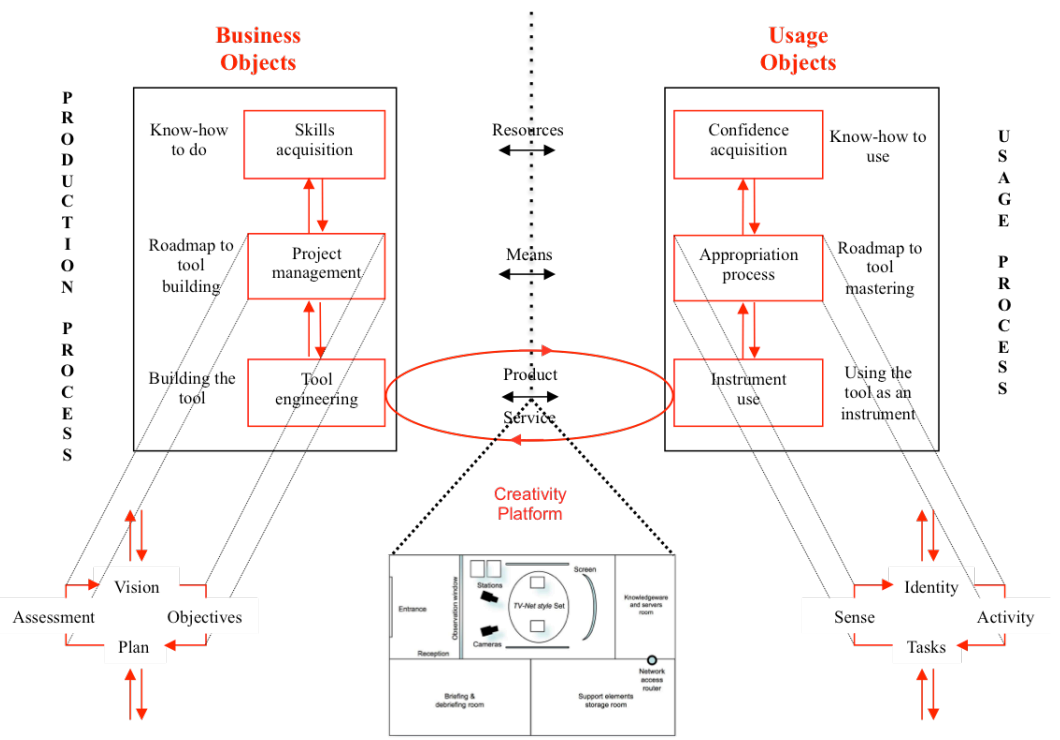

Fig. 8. Business and usage objects of the co-design methodology on a Creativity Platform

We will illustrate this co-design methodology used on a Creativity Platform with two examples taken in biodiversity informatics and in music instrumental e-learning.

\section{$6 \quad$ Findings}

Fifteen years ago at University of Reunion Island, some researchers of the mathematics and computer science team (LIM) decided to apply knowledge engineering and human-computer interaction to the enhancement of insular tropical environment and instrumental e-learning.

\section{Biodiversity informatics}

For biodiversity knowledge management or computer-aided taxonomy, we developed an Iterative Knowledge Base System platform called IKBS [25] with some taxonomists for modeling and describing their collections of corals (Figure 9). Knowledge 
bases are the written descriptions of collection specimens that can be compared with dissimilarity measures for classification or identification purpose.
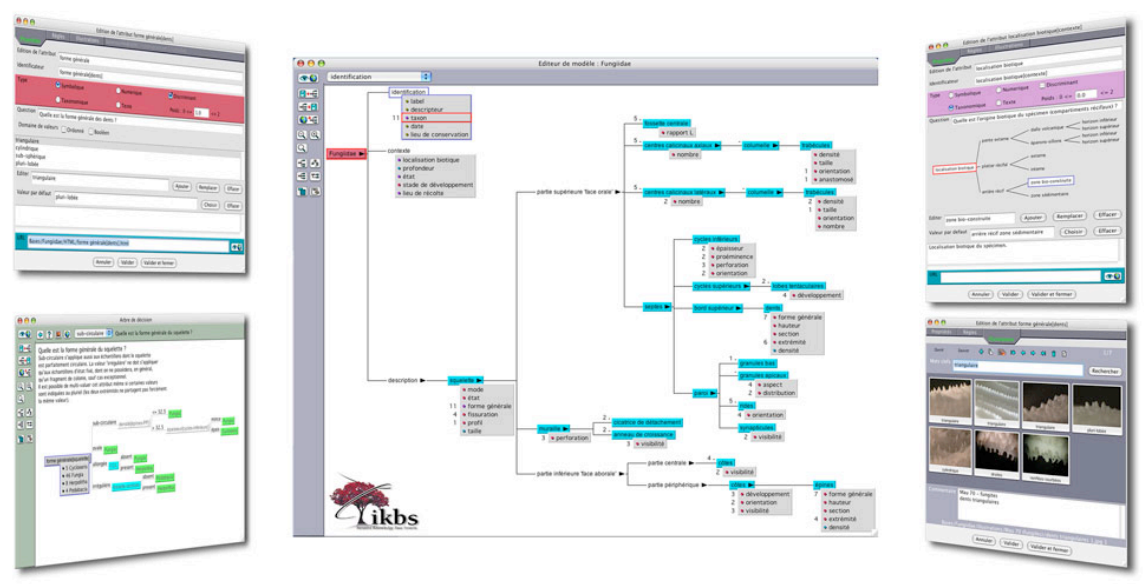

Fig. 9. IKBS

It is based on a knowledge acquisition method and an observing guide for describing biological objects, i.e. the descriptive logics in life Sciences [26]. Our descriptive logics must not be confused with description logics (RDF, OWL) of the Semantic $W e b$ because they are the rules of thumb of experts for making descriptive models (ontologies) and describing cases. The objective of this Research tool in Biodiversity Informatics is to help biologists classify and identify a specimen correctly from an expert viewpoint by using onto-terminologies (ontologies + thesaurus). With IKBS, experts can use directly the tool as an instrument for making the job of knowledge transmission, i.e. build a knowledge base and illustrate it (Figure 10).

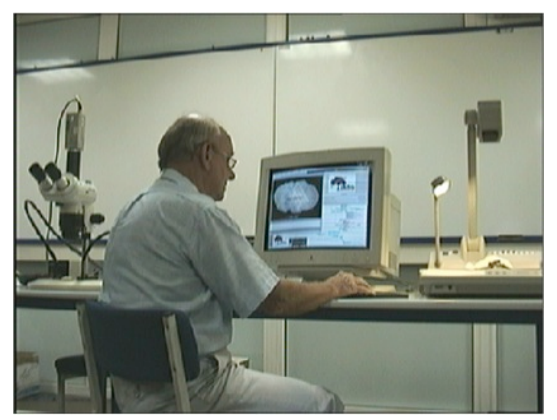

Fig. 10. IKBS can be used directly by experts, here on corals

But the teaching of biological objects appeared to be a real bottleneck in the decision help process. The interpretation problem of specimen descriptions made by specialists emerges when the knowledge base is put in the hands of other biologists: these sub- 
jects are not able to observe and describe biological objects with the same know-how and accuracy, thus leading to wrong identifications. On the usage side of co-design, a new co-learning method was then required based on sharing observation know-how rather than transmit knowledge.

The Learning problem from the end-user viewpoint is to know how to observe these objects in order to identify correctly the name of the species. This task is complex and needs help from the specialists who know by experience where to observe correctly the "right characters". By taking care of this knowledge transmission bottleneck, we enter the domain of Sign management for getting more robust results with end-users. Our idea of Sign management is to involve end-users with researchers and entrepreneurs for making them participate to the design of the product/service.

The problem we have to face with when making knowledge bases is that their usefulness depends on the right interpretation of questions that are proposed by the system to obtain a good result. Hence, in order to get correct identifications, it is necessary to acquire qualitative descriptions. But these descriptions rely themselves on the observation guide that is proposed by the descriptive model. Moreover, the definition of this ontology is dependent upon easy visualization of descriptive logics.

At last, the objects that are part of the descriptive model must be explained in a thesaurus for them to be correctly interpreted by targeted end-users. Behind each Object, there is a Subject that models this Object and gives it an interpretation. In life sciences, these objects can be shown to other interpreters and this communication between Subjects is compulsory for sharing interpretations, and not only transmitting knowledge (Figure 11).

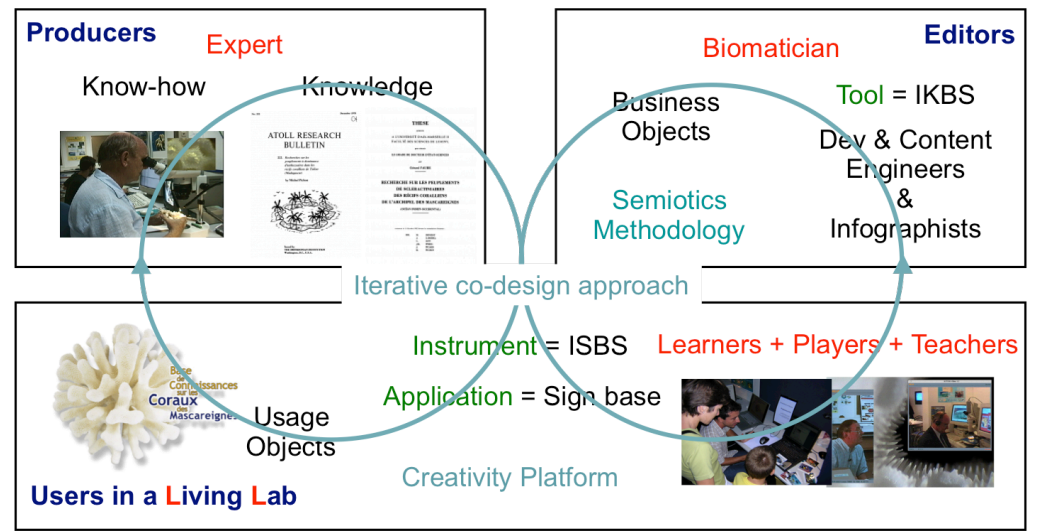

Fig. 11. The Sign management process for coral objects' interpretation

In this new frame, the IKBS project (Iterative Knowledge Base System) will become an ISBS project (Iterative Sign Base System). Its aim is to co-design a Sign Base for Biodiversity management (BSB) rather than a Knowledge Base (KB) with the interactions coming from a community of biologists and amateurs on a Creativity Platform. With ISBS, teachers and learners can play together to share their interpretations of observations. This project will benefit from the long experience we accumulated in the field of Mascarene Corals and Plants identification [27]. 
The challenge of Sign management for Science observation such as Systematics is to involve all types of end-users in the co-design of Sign bases for them to be really used (e-service). It is why we, as biologists and computer scientist (biomaticians), emphasize the instantiation of a Living Lab in Teaching and Learning at University of Reunion Island for sharing interpretations of objects and specimens on the table rather than concepts and taxa in the head of subjects.

\section{Instrumental e-learning}

Sharing Signs is particularly relevant in artistic fields, where a perfect synchronization between gestures, senses and feelings is essential in order to produce original and beautiful works.

In this frame, the @-MUSE project (@nnotation platform for MUSical Education) aims at constituting a Musical Sign Base (MSB) with the interactions coming from a community of musicians. This project benefits from the experience we accumulated in the field of instrumental e-learning in Reunion Island, from various mock-ups to complete projects such as e-Guitare or e-Piano [28]. Figure 12 sums up our research process in this domain, based on a Creativity Platform [29].

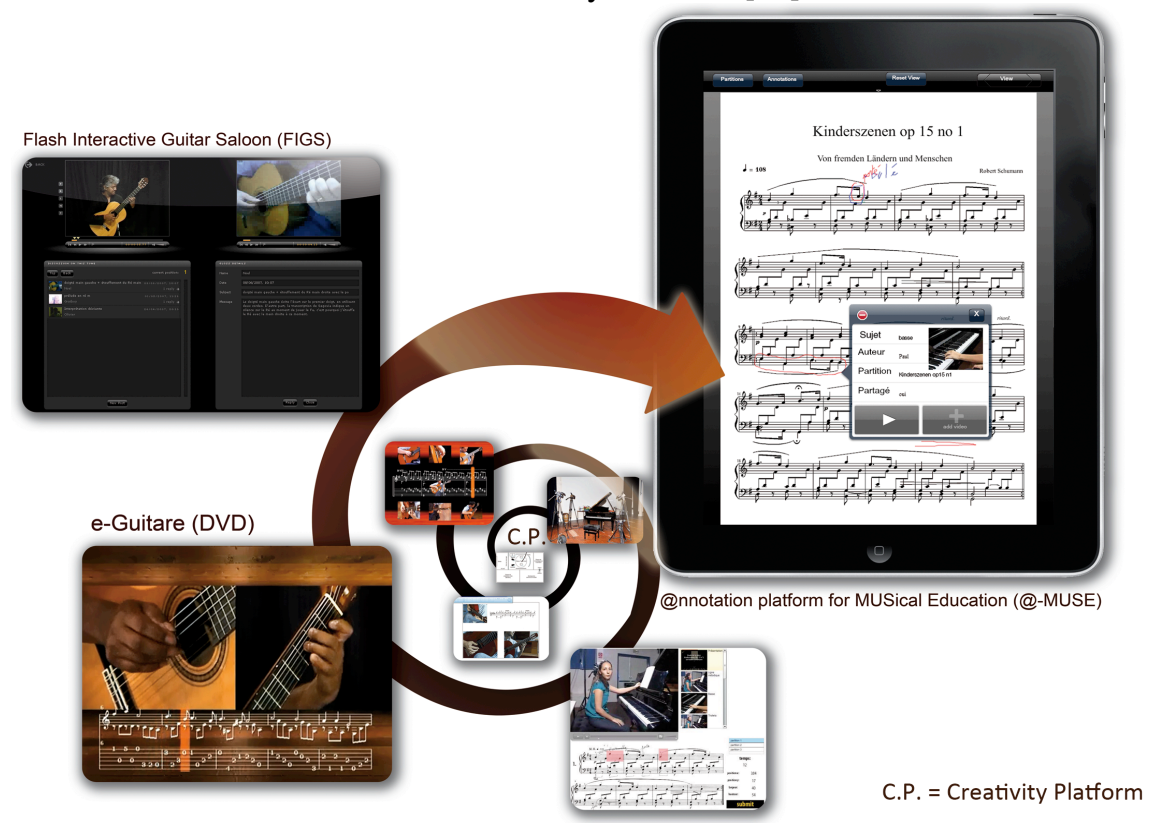

Fig. 12. Instrumental e-Learning services co-designed on a Creativity Platform (CP)

While the different versions of e-Guitare were more centered on the teacher performance, the FIGS (Flash Interactive Guitar Saloon) service was more axed on the dialog between learners and teachers through an online glosses system. What principally emerged from these projects was the need to facilitate the creation and maintenance of new content on the platform. Indeed, while those projects required the intervention of 
computer scientists and graphic designers in order to create high-quality resources, @-MUSE aims at empowering musicians into creating and sharing their lessons by themselves, on the basis of a common frame of reference: the musical score.

To do so, we designed a MSB. It consists in a set of annotated performances (specimen, or instance) each related to a given musical work (species, or class). This base can be used to compare various performances from music experts or students, and also to dynamically build new music lessons from the available content. To do so, we define a Musical Sign (MS) [30], as an object including a content (a musical performance or demonstration), a form (a score representing the played piece) and a sense (the background experience of the performer, what he or she intends to show) from the viewpoint of a subject (the creator of the Sign).

Figure 13 describes the composition of a MS that can be shared on the platform through a multimedia annotation. Indeed, the principle of @-MUSE is to illustrate abstract scores with indexed multimedia content on top of MusicXML format [31] in order to explicit concretely how to interpret them. Besides, as shown on Figure 13, multimedia annotations embed all three components of a Sign (data, information and sense). This procedure is inspired from a common practice in the music education field, which consists in adding annotations on sheet music in order to remember tips or advice that were validated during the instrumental practice [32].

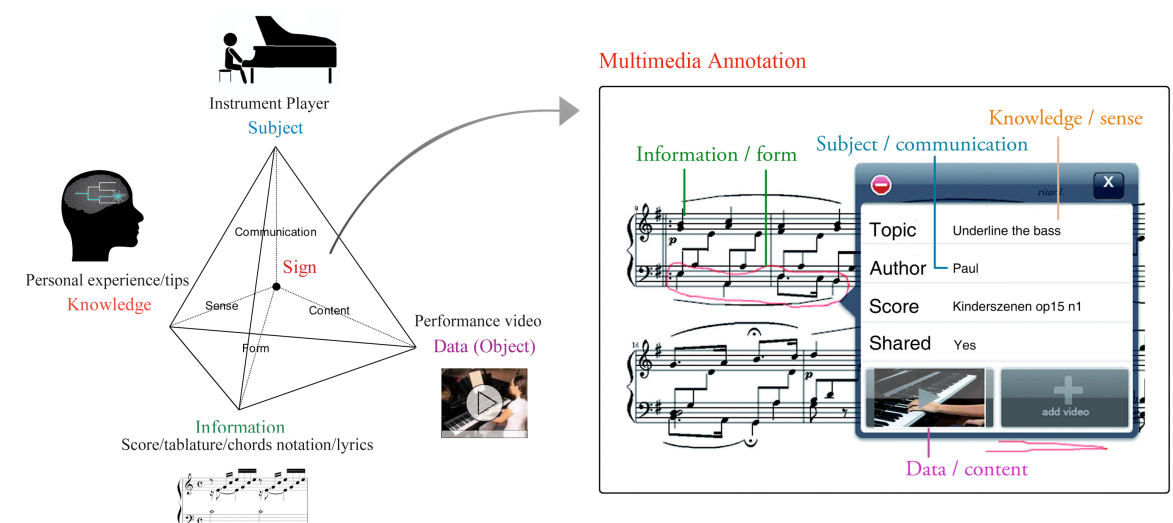

Fig. 13. The musical sign tetrahedron illustrated with a multimedia annotation on @-MUSE

Grounding the @-MUSE service on this practice insures a transparent and natural usage for musicians who already annotate their scores by hand, and additionally enables them to show what they mean using multimedia features. As such, @-MUSE empowers musicians into creating their own interactive scores, using for instance mobile tablets equipped with webcams (@-MUSE prototype [33]).

Collaborative aspects are also essential in music learning, where one progresses by confronting his performances to others'. In this frame, managing Signs rather than Knowledge is particularly relevant, as there is no "absolute truth" in artistic fields: each interpretation can lead to technical discussions between musicians, and their 
negotiations should be illustrated with live performances to be shown, then understood.

\section{From knowledge transmission to sign sharing}

Knowledge is subjective in the paradigm of Sign management: it cannot be taken for granted without putting it into use, mediated and negotiated with other Subjects on a meeting place, which we called a Creativity Platform. What can be managed is called descriptive or declarative knowledge: it is the communication of justified true beliefs propositions from one Subject made explicit. The formal interpretation process from observation to hypotheses, conjectures and rules is called signification of knowledge on the human communication side of the Sign. It is called representation or codification of knowledge on the machine information side of the Sign. Apart from being described, this interpretation process can be shown with artifacts to illustrate the description ("draw me a sheep", says the little prince!). Sign management wants to enhance this aspect of multimedia illustration of interpretations to facilitate transmission and sharing of knowledge through the communication of the Subject (see the fourth communication part of the sign in Figure 4).

In knowledge management, propositional knowledge is taken mostly in the sense of scientific knowledge, considered as objective in scientific books, and providing the know-that or know-what. Ryle in [34] has shown that this is confusing. In the sense of subjective knowledge taken as "I know that or I know what", there is the other sort of knowledge called know-how. It is "the knowledge of how to do things", i.e. what the subjects can show through their interpretations when they practice their activity (there is a difference between the recipe and the cooking of the recipe, isn't it?). And some people do the activity better than others. They are called the experts. As such, knowhow is closer to data (Praxis) and information (Techne) than to knowledge (Scientia). Finally, know-how and know-that or know-what are different categories of knowledge and should not be conflated [35]. Knowledge synthesizes what makes sense in the head of skilled persons for doing well the tasks of their activity.

Starting from these differences of interpretations about the term of knowledge, and considering the domain of activity that we want to deal with, i.e. education with ICT, we prefer to focus on managing interpretations, and firstly the good ones from professors. Sign management manages live knowledge, i.e. subjective objects found in interpretations of real subjects on the scene (live performances) rather than objective entities found in publications (bookish knowledge).

Sign or know-how management produces sign bases that are made of interpretations for knowing how-to-do things with multimedia content and not only knowing what are these things in textual Knowledge bases.

Sign management makes explicit the subjective view of doing arts and sciences. Our aim is to compare different interpretations of subjects about objects through transmitting and sharing them on a physical and virtual space dedicated to a special type of e-service, i.e. in instrumental e-learning or biodiversity informatics.

As shown in music and biodiversity Teaching and Learning, if we want to innovate with people, we should use the concept of Sign management rather than Knowledge 
management, because the paradigm shift is to pass from knowledge transmission to sign sharing by managing know-how.

Since several years in computer-aided systematics, we proposed a knowledge management methodology based on a top-down transmission of experts' knowledge, i.e. acquisition of a descriptive model and structured cases and then processing of these specimens' descriptions with decision trees and case-based reasoning. We designed a tool called IKBS for Iterative Knowledge Base System to build knowledge bases. But the fact is that Knowledge is transmitted with text, not shared with multimedia, and there is a gap between interpretations of specialists and end-users that prevents these lasts from getting the right identification.

More recently in instrumental e-learning, we focused on the need to show gestural know-how with interactive multimedia contents to play correctly a piece of music, by annotating electronic scores with @-MUSE. This pedagogical approach is based on a gloss system on the Web that can be indexed in codified musical notation.

Today, we prefer to deliver a Sign management method for Teaching and Learning how to identify these collection pieces (specimens or scores) on a Co-Design or Creativity Platform. This bottom-up approach is more pragmatic and user-centered than the previous one because it implicates end-users at will and is open to questions and answers. The role of biological and musical experts is to show amateurs how to play, observe, interpret and describe these art and science works. The responsibility of semioticians (the new cogniticians) is to store and share experts' interpretations of their observation and playing, i.e. know-how rather than knowledge in sign bases with multimedia annotations for helping them to define terms, model their domain, and allow end-users to interpret correctly the objects.

\section{Conclusion}

As computer scientists and knowledge engineers, we want to design a new Iterative Sign Base System: ISBS = IKBS + @-MUSE.

It will be the kernel of our Information Service for defining ontologies and terms, describing pieces work, classifying them with machine learning techniques, and identifying the name through a multimedia interactive questionnaire. The objective of such a tool is to become an instrument in users' hands for monitoring biodiversity in the fields with the National Park of Reunion Island [36], and music at home with the Regional Music Conservatory [37].

For achieving this, we stressed on the importance of reducing the gap between interpretations of teachers (specialists) and learners (amateurs) to get the right identification name and then access to information in databases, or to get the correct gesture that gives the right sound for playing music. This pedagogical effort must concretize itself on a Co-Design or Creativity Platform, which is the Living Lab meeting place for teachers, players and learners, and where these people can manipulate the objects under study, test the proposed e-services and be guided by experts' advices. The teacher is a producer who communicates his skilled interpretation of an activity at different levels of perception: psychological motivation, training action, and reason- 
ing feedback. The players are designers-developers editors that produce multimedia contents of the expert tasks to perform a good result and index them in a sign base. The learners are prosumers (producers and consumers) who experiment the sign bases on the physical or virtual Co-Design Platform and tell about their use of the tool to domain experts, ergonomists and anthropologists, in order to improve the content and the functionalities of the mock-ups and prototypes.

Behind each Object to observe, play and describe, there is a Subject who expresses himself and interprets an object by adding his proper signification. This is why we differentiate the Semantic Web, which is the business object approach (the Web of things) represented "objectively" with some description logics (formal syntax for ontologies and cases), and the Semiotic Web that is the usage object approach (the Web of Signs) signified by some descriptive logics of the domain (meaningful process of performance), and which are more subjective. The purpose of the Semiotic Web is to facilitate a consensus between community members, without forgetting that some interpreters are smarter than others in performing a Science or an Art. Their expertise will be visible if users show their interpretations of objects by multimedia artifacts (HD video, 3D simulation, annotated drawings or photos), and if other endusers can ask questions on their know-how and negotiate interpretations. It is why in the frame of natural and cultural heritage enhancement, we proposed to develop Teaching and Learning by Playing e-services with people in a Living Lab by using Sign management on a Co-design Platform at the University of Reunion Island [38].

In the post-industrial age of our digital society, designing new services on the Web is crucial for regional territories in order that they become more attractive, competitive, and also more sustainable in the global economy. But up to now, innovation is mainly seen as a linear technological downstream process, centered on enterprises (clusters) and not viewed as an iterative usage upstream process, focused on individuals (Living Labs).

The form of LL is attractive because it is an ecosystem based on democratizing innovation with people. User-centered design innovation means that some people, called lead-users, want to innovate for themselves. It has been shown that these persons make most of the design of new services, and only a few come from manufactures.

The content of LL is competitive because the best solutions from lead-users are experimented in real time by making situational analyses in "usage laboratories". Mockups and prototypes are tested and instrumented to get the best-customizedpersonalized products and services. For example, the game design (user interaction) and interfaces of 3D multimedia video games benefit greatly from the analysis of feedbacks coming from end-users in communities of practice. So, the success of the eservice does not depend only on the technical success: it has more to do with the quality of human-computer interaction provided with the technology.

At last, the sense of LL should be more sustainable, i.e. to render a useful and free service before being profitable, i.e. not only based on a monetary basis but also on trust and reputation. This characteristic is fundamental in the meaning of open access innovation to serve a mission within the scope of products and services made by pub- 
licly funded universities. The ultimate value would be to create a form of digital companioning in order to reposition human sharing at the core of technology race.

\section{References}

1. http://en.wikipedia.org/wiki/Lisbon_Strategy

2. Kok, W.: Facing the challenge, the Lisbon strategy for growth and employment, Report from the High Level Group (2004)

3. Luyckx Ghisi, M.: The knowledge society: a breakthrough towards genuine sustainability, Editions India, Arunchala press. Cochin, Kerala (2008)

4. http: //www.openlivinglabs.eu/news / when-infrastructure-meets-user-new-lovestory-making

5. http://www.ictusagelab.fr/ecoleLL/content/literature

6. Bergvall-Kåreborn, B., Ihlström, E.C., Ståhlbröst, A., Svensson, V.: A milieu for innovation: defining living labs. In: 2nd ISPIM innovation symposium: Simulating recovery - the Role of innovation management, 6-9 December, 12 p., New York (2009)

7. Følstad, A.: Living Labs for innovation and development of information and communication technology: A literature review, The Electronic Journal for Virtual Organizational and Networks, vol. 10, special issue on Living Labs, pp. 99-131 (2008)

8. Santoro, R., Bifulco, V: ESoCE-NET White Paper: The "Concurrent Innovation" paradigm for Integrated Product/Service Development (2006) [http://www.esoce.net].

9. http://eit.europa.eu/eit-community/eit-glance/mission

10. http://eit.europa.eu/eit-community/eit-ict-labs

11. http://www.eitictlabs.eu/about-us/strategy/the-knowledgetriangle

12. Adamson, L., Flodström, A.: Teaching for Quality in the Knowledge Triangle - European Institute of Innovation and Technology's (EIT) coming Quality Assurance and Learning Enhancement Model. Conference proceedings The future of Education, Florence, Italy, 1617 June (2011)

13. Peirce, C.S.: Elements of Logic, In: Hartshone, C. H., Weiss, P. (eds.) Collected Papers of C.S. Peirce (1839-1914). The Belknap Press, Harvard Univ. Press, Cambridge, MA (1965)

14. von Uexküll, J.: Theoretical Biology. pp. xvi+362. Kegan Paul, Trench, Trubner \& Co., London (1926) (Transl. by D. L. MacKinnon. International Library of Psychology, Philosophy and Scientific Method)

15. Farreny, H.: Les Systèmes Experts: principles et exemples: Cepadues-Editions, Toulouse (1985)

16. Shapiro, J. A.: Bacteria are small but not stupid: cognition, natural genetic engineering and sociobacteriology, Studies in History and Philosophy of Biological and Biomedical Sciences 38(4), 807-819 (2007)

17. Maslow, A.H.: A Theory of Human Motivation, Psychological Review 50(4), 370-96, (1943)

18. Engeström, Y.: Learning by expanding: an activity-theoretical approach to developmental research, Orienta-Konsultit Oy, Helsinki (1987)

19. Barbieri, M.: Introduction to Biosemiotics. The new biological synthesis. Springer (2007)

20. Sebeok, T.A.: Umiker-Sebeok J. (eds.): Biosemiotics: The Semiotic Web 1991. Mouton de Gruyter, Berlin (1992) 
21. Saussure de, F.: Nature of the Linguistics Sign, In: Bally, C., Sechehaye, A. (eds.), Cours de Linguistique Générale, McGraw Hill Education (1916)

22. University of Reunion Island Living Lab vision (2011), http: //www.slideshare.net/conruyt/urlltl

23. New Media Consortium (2013), http://www.nmc.org/publications

24. Sébastien, O., Conruyt, N., Grosser, D.: Defining e-services using a co-design platform: Example in the domain of instrumental e-learning. Journal of Interactive Technology and Smart Education 5(3), 144-156 (2008) ISSN 1741-5659

25. Conruyt, N., Grosser, D.: Knowledge management in environmental sciences with IKBS: application to Systematics of Corals of the Mascarene Archipelago, Selected Contributions in Data Analysis and Classification, Series: Studies in Classification, Data Analysis, and Knowledge Organization, pp. 333-344, Springer (2007) ISBN: 978-3-540-73558-8

26. Le Renard, J., Conruyt, N.: On the representation of observational data used for classification and identification of natural objects. In: New Approaches in Classification and Data Analysis, Studies in Classification, Data Analysis, and Knowledge Organization, pp. 308315 Springer (1994) ISBN: 978-3-540-58425-4

27. http://coraux.univ-reunion.fr/http://mahots.univ-reunion.fr/

28. http://e-guitare.univ-reunion.fr/ e-piano.univ-reunion.fr/

29. Conruyt, N., Sébastien, O., Sébastien, V. Sébastien, D. Grosser, D., Calderoni, S., Hoarau, D., Sida, P.: From Knowledge to Sign Management on a Creativity Platform, Application to Instrumental E-learning. In: 4th IEEE International Conference on Digital Ecosystems and Technologies, DEST, Dubaï, UAE, April 13-16 (2010)

30. Sébastien, V., Sébastien, D., Conruyt, N.: Dynamic Music Lessons on a Collaborative Score Annotation Platform, In: The Sixth International Conference on Internet and Web Applications and Services, ICIW, St. Maarten, Netherlands Antilles, pp. 178-183 (2011)

31. Castan, G., Good, M., Roland, P.: Extensible Markup Language (XML) for Music Applications: An Introduction, The Virtual Score: Representation, Retrieval, Restoration, pp. 95-102. MIT Press, Cambridge (2001)

32. Winget, M. A.: Annotations on musical scores by performing musicians: Collaborative models, interactive methods, and music digital library tool development, Journal of the American Society for Information Science and Technology (2008)

33. Sébastien, V., Sébastien, P., Conruyt, N.: @-MUSE: Sharing musical know-how through mobile devices interfaces. In: 5th Conference on e-Learning Excellence in the Middle East, Dubaï (2012)

34. Ryle, G.: The concept of mind. Hutchinson, London (1949)

35. Callaos, N.: The Essence of Engineering and Meta-Engineering: A Work in Progress. In: The 3rd International Multi-Conference on Engineering and Technological Innovation: IMETI 2010, Orlando, Florida, USA, June 29-July 2 (2010)

36. Reunion National Park (2007), http: / /www . reunion-parcnational.fr

37. CRR, http:// http://conservatoire.regionreunion.com

38. www.slideshare.net/conruyt/

living-lab-and-digital-cultural-heritage 